Some years ago a reference list on tho subject was made in England and it was found that it had little biological importance, in that almost all the references concerned clinical or surgical details of individual human cases treated. In a few countrios a hydatid registry has been set up; here again the value of the effort is restricted, in that the finding of a human case is not a strong aid in the finding of the source of the worm, owing to the time lag, the difficulty in tracing movements of man and animal, movements of contacts and details of the range of possible sources. In a country where the risk is great, compulsory worm treatment of dogs, regulations concerning the necessary hygiene to prevent the access of the worm to susceptible hosts and general publicity on the subject yield results.

The magnitude of the problem is indicated by the existence of the National Hydatids Council in Now Zealand and especially by the contents of the report for 1961-62 now issued. All the relevant bodies in the country are represented on the Council: the veterinary profession, the Government and industrial agricultural bodies and, of course, the Department of Hoalth and the General Medical Council. There is a National Hydatid Testing Station, where very large numbers of samples are dealt with regularly. The report is issued in accordance with the Hydatids Act, 1959: the Hydatids Amendment Act, 1961, strengthened tho Act.

A table giving the results of tests for the worm in household pets shows that it was present in 554 dogs. Under the scheme for control, 300 county and municipal councils are organized in 87 Hydatid Control Authority Groups, employing 121 hydatid control officors, for observations on a quarter of a million dogs. Of 541,021 fæcal samples tested, 1.86 per cent yielded positivo results. 109 human cases, including 32 old cases, occurred in 1959, and 102, including 44 old cases, in 1960 . Before control measures wore in operation it was estimated that one dog in four carried the worm. The measures taken, therefore, are considered to be valuable.

\title{
FOREST INFLUENCES
}

\begin{abstract}
TN recent years more and more attention has been 1 directed to the subject of forest influences as a result of an appreciation of its importance in the assessment of forest and other land use policies. Much of the fruits of these studies is now available in a recent publication issued by the Food and Agriculture Organization of the United Nations*.

Forest Influences is a composite work of experts which is introduced by the late Aldo Pavari, that Italian forest research worker of international renown. Pavari directs attention to the complex relationship between environment and forest vegetation, and he summarizes the in fluence of forests on climate, soil and wator supplies. There are two chapters on water action and movement in the forest and their bearing on land use. Data from selected experiments indicate the effect of forest cover in reducing overland flows of water and thereby spreading stream run-off over a longer period. Thus the presence of vegetation may exert a great effect on stabilizing soil and regulating streams, and the required density of the vegetation depends on whether the primary object of land management is flood regulation and soil stabilization or to obtain maximum water yields compatible with soil

* Food and Agriculture Organization of the United Nations. FAO Forestry and Forest Products Studies, No. 15: Forest Influences. Pp. xix + 307. (Rome: Food and Agriculture Organization of the United Nations; London: H.M.S.O., 1962.) 3 dollars; 158.
\end{abstract}

stability and flood regulation. As the presence or absence of vegetation may exert a great influence on soil stability and regulation of stream flow, it is essential for the land manager to maintain minimum densities of vegetation above the critical level of deterioration.

Joseph Kittredge, one of the contributors, is already well known for his authoritative work (Forest Influences: 1948), and his chapter on the influence of the forest on the weather brings that subject up to date. There is a very good chapter on shelterbolts although it bears the rather curious title "Trees Outside the Forest". The subjectmatter is well supported by statisties and diagrams. In the concluding chapter, on the evaluation of the utility of forest influences, T. Francois profoundly states: "The forest is made up of a combination of benefits, and this is precisely what distinguishes it from other land uses and imparts to such land use its economic as well as physical and social value".

The Food and Agriculture Organization's publication is a praiseworthy contribution as it explains the subject in an authoritative and easily understood manner, and this, surely, is a subject which is of very great importance to all those who, in any way, are concerned with land use administration and practice, and to research workers. Printing and illustrations are of a very high standard and a most useful bibliography is included. C. J. TAYLOR

\section{WHITE-LIGHT VERSUS NARROW-BAND OBSERVATIONS OF THE POLARIZATION OF THE ZODIACAL LIGHT}

\author{
BY J. L. WEINBERG
}

Department of Astrophysics and Atmospheric Physics, University of Colorado and High Altitude Observatory, Boulder, Colorado

$\mathrm{I}$ MPROPER correction of sky brightness observations for the airglow line and continuum components will result in a degree of polarization, $p$, which is not characteristic of the zodiacal light. Uneertain and, in some cases, unknown absolute intensities for much of the airglow lines, bands and continua make any attempt to correct white-light observations subject to considerable error. These corrections are difficult to make even when a narrow-band filter is used. To illustrate the influence of the airglow radiation on the polarization inferred for the zodiacal light we have taken a sample from observations of the zodiacal light (brightness and degree and orientation of the plane of polarization) which were obtained with a scanning photoelectric polarimeter on $10,000 \mathrm{ft}$. Mt. Haleakala, Hawaii, over the period November 1961May 1962.

This zodiacal light photometer normally makes use of an interference filter with a peak transmission of 78 per cont at $5300 \AA$ and an equivalent width (the width for 100 per cent transmission) of $70 \AA$. The band-pass of the photometer as a whole (minus filter) is approximately $3000 \AA$ centred on $4800 \AA$ and is determined by the transmission characteristics of the optical components and by the response curve (S-11) of the photomultiplier.

Representative almucantar surveys taken in whitelight (with the sky brightness signal electrically attenu- 